\title{
PEMANFAATAN LIMBAH PADAT SLAG NIKEL, ABU SEKAM PADI, DAN FLY ASH MENJADI PAVING BLOCK
}

\author{
Yusril Aprianto, Rita Dewi Triastianti
}

\section{INTISARI}

PT. Aneka Tambang Pomalaa Kabupaten Kolaka Propinsi Sulawesi Tenggara menghasilkan limbah buangan hasil pada pengolahan bijih nikel berupa slag, selama ini slag hanya digunakan sebagai bahan timbunan yang kurang memiliki nilai ekonomis. Jumlah slag nikel kian hari kian menumpuk, karena setiap proses pemurnian satu ton produk nikel menghasilkan limbah padat 50 kalinya, setara 50 ton. Slag nikel dapat dijadikan sebagai pengganti pasir pada paving block dengan penambahan abu sekam padi dan fly ash yang berasal dari PLTU PT.

Paving block yang telah di keringkan selama 24 jam kemudian diberikan perlakuan (perendaman) selama 17 hari dan selanjutnya dikeringkan kembali dan siap untuk dilakukan uji kuat tekan paving dengan menggunakan alat uji tekan beton merek ENERPAC. Paving block terdiri dari lima (5) sampel dengan kode sampel menggunakan abjad A,B,C,D,dan E, dengan komposisi yang berbeda tiapsampel. Komposisi sampel A semen 25\%, Slag 25\%, abu sekam padi 25\% dan Fly ash $25 \%$. Komposisi sampel B semen 25\%, Slag 45\%, Abu sekam padi 15\%, dan Fly ash $15 \%$. Komposisi sampel C semen 25\%, Slag 15\%, Abu sekam padi 45\%, dan Fly ash $15 \%$. Komposisi sampel D semen 25\%, Slag 15\%, Abu sekam padi 15\%, dan Fly ash $45 \%$. Komposisi sampel E semen 25\%, Slag 35\%, Abu sekam padi 25\%, dan Fly ash $15 \%$

Paving block dengan kode sampel C campuran $45 \%$ abu sekam padi, $25 \%$ semen, $15 \%$ slag nikel dan $15 \%$ ply ash dengan waktu perendaman selama 17 hari menghasilkan kuat tekan paving block sebesar $15731 \mathrm{~kg} / \mathrm{cm} 2$, begitu pula pada persentase paving block dengan kode sampel B campuran $25 \%$ semen, $45 \%$ slag, dan $15 \%$ fly ash dengan waktu perendaman yang sama selama 17 hari mengahasilkan kuat tekan paving block sebesar $15731 \mathrm{~kg} / \mathrm{cm} 2$, tetapi dua sampel ini menunjukan berat yang berbeda. Paving block dengan penambahan beberapa persentase abu sekam padi, slag nikel, dan ply ash menunjukkan hasil kuat tekan yang berbeda-beda. Kuat tekan terbaik ditunjukan pada kodesampel A dengan penambahan $25 \%$ abu sekam padi, $25 \%$ slag nikel, dan $25 \%$ ply ash menunjukkan perilaku kuat tekan yang cukup baik dimana nilainya kuat tekannya22238 kg/cm2.

Kata kunci :Slag nikel, Abu sekam padi, Fly ash,Paving block

\section{UTILIZATION OF SOLID WASTE SLAG NICKEL, RICE BOTH DRINKS, AND FLY ASH BECOME PAVING BLOCK}

\footnotetext{
ABSTRACT

PT. Aneka Tambang PomalaaKolaka regency of Southeast Sulawesi Province produces waste from nickel ore processing in the form of slag, so far slag is only used as a pile material that has less economic value. The amount of nickel slag is increasingly piled up, as each refining process of one ton of nickel products produces 50 solids of solid waste, equivalent to 50 tons. Nickel slag can be used as a substitute for sand on paving block with the addition of rice husk ash and fly ash from PLTU $P T$.

The dried paving block for 24 hours was then treated (immersed) for 17 days and then dried again and ready for a compressive strength test of paving using an ENERPAC brand concrete press test apparatus. Paving blocks consist of five (5) samples with sample codes using the $A, B, C, D$, and $E$ alphabets, with different compositions of each sample. The sample composition of A cement 25\%, 25\% slag,
} 
$25 \%$ rice husk ash and $25 \%$ Fly ash. The sample composition is $25 \%$ Cement B, $45 \%$ Slag, $15 \%$ rice husk ash, and 15\% Fly ash. The composition of C sample is $25 \%$ Cement, Slag 15\%, Ash rice husk 45\%, and Fly ash 15\%. The sample composition is $D$ cement 25\%, Slag 15\%, Ash husk rice 15\%, and Fly ash 45\%. The sample composition of E cement 25\%, Slag 35\%, rice husk ash $25 \%$, and Fly ash $15 \%$

Paving block with sample code C mixture $45 \%$ rice husk ash, 25\% cement, $15 \%$ nickel slag and $15 \%$ ply ash with immersion time for 17 days yielding compressive strength of paving block $15731 \mathrm{~kg} / \mathrm{cm} 2$, as well as percentage of paving block with sample code B mixture of $25 \%$ cement, $45 \%$ slag, and $15 \%$ fly ash with the same immersion time for 17 days resulted in a compressive strength of paving block of $15731 \mathrm{~kg} / \mathrm{cm} 2$, but these two samples show different weights. Paving blocks with the addition of several percentages of rice husk ash, nickel slag, and ply ash show different compressive strength results. the best compressive strength is shown in code sample A with the addition of 25\% rice husk ash, 25\% nickel slag, and $25 \%$ ply ash indicates good compressive strength in which the compression value is $22238 \mathrm{~kg} /$ cm2.

Keywords: Nickel slag, rice husk ash, Fly ash, Paving block

\section{A. PENDAHULUAN}

Sektor industri merupakan salah satu sektor penting dalam pembangunan perekonomian di Indonesia.Berbagai macam industri mengalami perkembangan yang cukup pesat. Salah satu bidang industri yang berkembang adalah industri kontruksi khususnya pembangunan infrastruktur dan properti yang membutuhkan material salah satunya adalah paving block.

Paving block adalah suatu komposisi bahan bangunan yang terbuat dari campuran semen portland atau bahan perekat hidrolis lainnya, air dan agregat dengan atau tanpa bahan tambahan lainnya yang tidak mengurangi mutu beton tersebut (SNI 03-0691-1996). Paving block adalah bahan bangunan yang dibuat dari campuran semen, pasir dan air, sehingga karakteristiknya hampir mendekati dengan karakteristik mortar. Mortar adalah bahan bangunan yang dibuat dari pencampuran antara pasir dan agregat halus lainnya dengan bahan pengikat dan air yang didalam keadaan keras mempunyai sifat- sifat seperti batuan (Artiyani 2010).

Penggunaan paving block sebagai alternatif pengerasan jalan lingkungan akhir- akhir ini mulai marak digunakan. Meningkatnya kebutuhan akan pengerasan jalan mengharuskan penelitian lebih lanjut untuk menghasilkan kualitas mutu paving block yang lebih baik.Agregat adalah material granular, misalnya pasir, kerikil, batu pecah, dan slag tungku besi yang dipakai bersamasama dengan suatu media pengikat untuk membentuk suatu beton semen hidrolik atau adukan (SK-SNI-151991-03:4).

\section{B. TINJAUAN PUSTAKA}

\section{Paving Block}

Paving block adalah suatu komposisi bahan bangunan yang dibuat dari campuran semen portland 
atau bahan perekat hidrolis sejenisnya, air dan agregat atau bahan perekat-perekat lainnya yang tidak mengurangi mutu bata beton tersebut (SN1 - 03 - 0691 - 1989:1).

Paving block adalah bahan bangunan yang dibuat dari campuran semen, pasir dan air, sehingga karakteristiknya hampir mendekati dengan karakteristik mortar. Mortar adalah bahan bangunan yang dibuat dari pencampuran antara pasir dan agregat halus lainnya dengan bahan pengikat dan air yang didalam keadaan keras mempunyai sifat-sifat seperti batuan (Smith, 1979 dalam Malawi, 1996 dalam Artiyani 2010).

Paving block memiliki nilai estetika yang bagus, karena selain memiliki bentuk segiempat ataupun segibanyak dapat pula berwarna seperti aslinya ataupun diberikan zat pewarna dalam komposisi pembuatan. Paving block ini sendiri berfungsi untuk lantai yang banyak digunakan di luar bangunan serta tidak boleh retak-retak dan cacat.

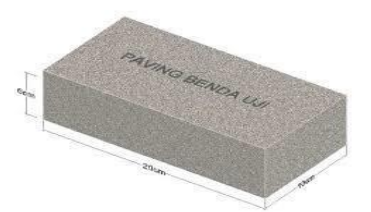

Gambar1. Bentuk dan ukuran paving block

\section{Slag Nikel}

Slag nikel merupakan salah

satu limbah padat dari hasil penambangan dan proses pengolahan nikel. Jumlah slag nikel kian hari kian menumpuk, karena setiap proses pemurnian satu ton produk nikel menghasilkan limbah padat 50 kalinya, setara 50 ton. Sehingga dari hasil limbah yang cukup banyak, dilakukan penelitian untuk menggunakan limbah padat tersebut sebagai bahan pembentuk beton, baik sebagai agregat kasar dan halus, ataupun sebagai bahan campuran semen. Sekitar $70 \%$ komposisi kimia slag nikel terdiri dari Silika 41,47\%, Ferri Oksida 30,44\% dan Alumina 2,58\%. Dengan komposisi silika yang cukup besar pada slag nikel, diharapkan proses hidrasi yang terjadi antara pasta semen dan agregat akan membentuk interface yang lebih sempurna, sehingga kehancuran beton tidak terjadi pada interface, atau kalaupun terjadi kehancuran pada interface diperlukan energi yang cukup tinggi, dengan kata lain akan diperoleh kekuatan beton yang cukup tinggi. Adapun pada pembentukan bongkahan slag nikel tersebut ada dua macam terak yang terbentuk, yaitu slag nikel yang berpori sekitar 2.835, sehingga dalam penggunaannya, agregat slag nikel dapat digunakan sebagai beton normal $(\gamma=2.400 \mathrm{~kg} / \mathrm{m} 3)$ dan beton berat $(\gamma=3.000 \mathrm{~kg} / \mathrm{m} 3)$ (Saptahari.S, 2005). 


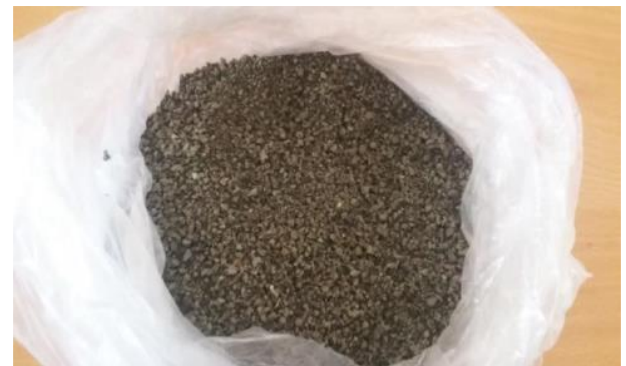

Gambar 2. Bentuk dan ukuran slag nikel

\section{Abu Sekam Padi}

Sekam padi merupakan bahan berligno selulosa seperti biomassa lainnya namun mengandung silika yang tinggi. Kandungan kimia sekam padi terdiri atas $50 \%$ selulosa, 25 $30 \%$ lignin, dan $15-20 \%$ silika (Ismail and Waliuddin, 1996). Sekam padi saat ini telah dikembangkan sebagai bahan baku untuk menghasilkan abu yang dikenal di dunia sebagai RHA (rice husk ask). Abu sekam padi yang dihasilkan dari pembakaran sekam padi pada suhu 4000-5000 C akan menjadi silika amorphous dan pada suhu lebih besar dari $10000 \mathrm{C}$ akan menjadi silika kristalin.

Sekam padi tidak dapat digunakan sebagai material pengganti pasir tanpa mengalami proses pembakaran. Dua faktor yang perlu diperhatikan pada proses pembakaran yaitu kadar abu dan unsur kimia dalam abu. Kadar abu menjadi penting sebab hal ini menunjukkan atau menentukan berapa jumlah sekam yang harus dibakar agar menghasilkan abu sesuai kebutuhan. Selama proses pembakaran sekam padi menjadi abu mengakibatkan hilangnya zat-zat organik yang lain dan menyisakan zat-zat yang mengandung silika. Pada proses pembakaran akibat panas yang terjadi akan menghasilkan perubahan struktur silika yang berpengaruh pada dua hal yaitu tingkat aktivitas pozolan dan kehalusan butiran abu. Penggunaan abu sekam padi dengan campuran yang sesuai pada semen akan menghasilkan semen lebih baik (Singh et al., 2002).

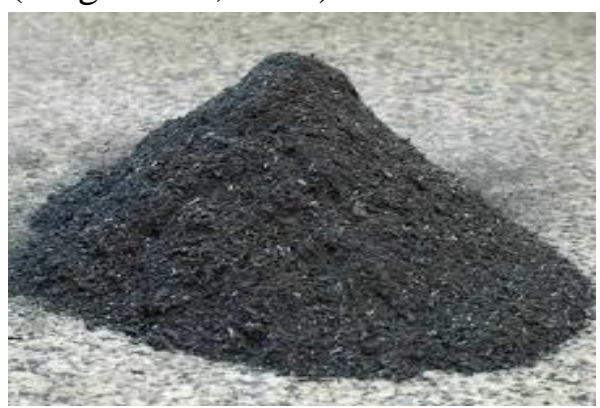

Gambar 3. Abu sekam padi

\section{Fly ash}

Fly ash merupakan satu bahan tambah (additive) yang cukup populer saat ini untuk digunakan sebagai :

a. pengganti sebagian semen dalam campuran beton

b. bahan untuk stabilisasi tanah ekspansif

Fly ash adalah bahanlimbah dari pembakaran batu bara, yang dikategorikansebagai limbah B3(PP No. 85 tahun 1999 tentang Pengelolaan Limbah Bahan Berbahaya dan Beracun). Batu bara, sebagai sumber penghasil fly ash, $\begin{array}{lll}\text { berdasarkan } & \text { ASTM } & \text { D.388 }\end{array}$ dikelompokkan menjadi 4, yaitu : 

a. batubara Lignitic
b. batubara Sub-bitumminous
c. batubara Bitumminous
d. batubara Antrachite

Limbah pembakaran batu bara sendiri terbagi atas 2 kelompok :

a. Bottom ash, yaitu abu berat

b. Fly ash, yaitu abu terbang/ringan

Fly ash terutama terdiri atas senyawa silicate glass yang mengandung silika ( $\mathrm{Si}$ ), alumina (Al), ferrum (fe), dan kalsium (Ca). Kandungan kecil senyawa lain yang terdapat dalam fly ash adalah magnesium (Mg), sulfur (S), sodium $(\mathrm{Na})$, potassium $(\mathrm{P})$, dan karbon $(\mathrm{C})$. Kandungan bahan berbahaya yang ada dalam fly ash antara lain : arsenic, berilium, boron, cadmium, chromium,cobalt, lead, mangan, merkuri, selenium, strontium, thallium, vanadium, juga mengandung dioksin dan senyawa $\mathrm{PAH}$ (polycyclic aromatic hydrocarbon).

Fly ash umumnya terdiri dari partikel solid yang berbentuk bulat, dan sebagian adalah partikel bulat berongga serta partikel bulat yang berisi partikel-partikel bulat lain yang lebih kecil. Ukuran partikel fly ash bervariasi mulai yang lebih kecil dari1 $\mu \mathrm{m}$ (micrometer) sampai yang lebih besar dari $100 \mu \mathrm{m}$ (beberapa literatur menyebutkan ukuran 0,5 $\mu \mathrm{m}-300 \mu \mathrm{m}$ ), dengan sebagian besar partikel berukuran kurang dari 20 $\mu \mathrm{m}$. Umumnya hanya sekitar $10 \%$ sampai 30\% ukuran partikel fly ash lebih besar dari $50 \mu \mathrm{m}$. Luas permukaan fly ash umumnya berkisar $300 \mathrm{~m} 2 / \mathrm{kg}$ - $500 \mathrm{~m} 2 / \mathrm{kg}$ fly ash, dengan batas bawah $200 \mathrm{~m} 2 / \mathrm{kg}$ dan batas atas $700 \mathrm{~m} 2 / \mathrm{kg}$.

Specific Gravity (Gs) fly ash bervariasi, ada beberapa institusi yang memberikan rentang nilai specific gravity, rentang terbesar yang diberikan dari institusi-institusi tersebut adalah antara 1,6-3,1. Pada umumnya specific gravity material fly ash berkisar antara 1,9-2,55. Massa jenis fly ash dalam kondisi loose berkisar $540-860 \mathrm{~kg} / \mathrm{m} 3$, dan dalam kondisi dipadatkan dengan penggetaran dalam kemasan pada umumnya mempunyai massa jenis $1.120-1.500 \mathrm{~kg} / \mathrm{m} 3$.

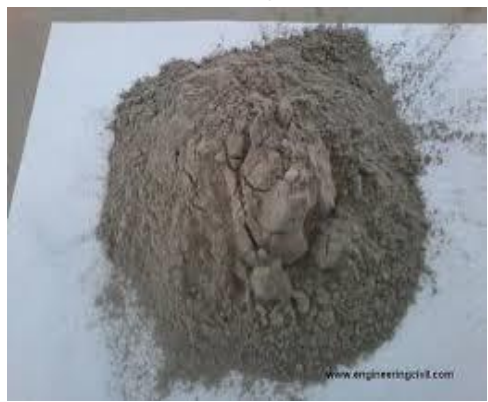

Gambar 4. Bentuk Fly Ahs

\section{METODE PENELITIAN}

\section{Waktu dan Tempat Penelitian}

Penelitian ini berlangsung antara bulan september sampai selesai. Penelitian dilakukan di Lingkungan worksop Percetakan Paving block yang Bertempat di PT. ANTAM Kota pomala, kolaka 
Sulawesi tenggara dan diuji di Laboratorium Teknik Sipil Jurusan Teknik Sipil Fakultas Teknik, Universitas Halu Oleo, kendari Sulawesi tenggara

\section{Jenis Penelitian}

Penelitian ini merupakan penelitian dalam bidang pemamfaatan limbah sisa pengolahan nikel, padi, dan PLTU yang berjudul "pemamfaatan limbah padat slag nikel, abu sekam padi, dan ply ash menjadi paving block" menggunakan metode eksperimen.

\section{Bahan Penelitian}

Bahan yang digunakan pada penelitian ini dapat dilihat pada tabel berikut:

Tabel 1. Bahan Penelitian

\begin{tabular}{|l|l|l|l|l|}
\hline $\begin{array}{l}\text { Sam } \\
\text { pel }\end{array}$ & $\begin{array}{l}\text { Seme } \\
\mathrm{n}\end{array}$ & $\begin{array}{l}\text { Slag } \\
\text { nikel }\end{array}$ & $\begin{array}{l}\text { Abu } \\
\text { sekam } \\
\text { padi }\end{array}$ & $\begin{array}{l}\text { Ply } \\
\text { ash }\end{array}$ \\
\hline $\mathrm{A}$ & $25 \%$ & $25 \%$ & $25 \%$ & $25 \%$ \\
\hline $\mathrm{B}$ & $25 \%$ & $45 \%$ & $15 \%$ & $15 \%$ \\
\hline $\mathrm{C}$ & $25 \%$ & $15 \%$ & $45 \%$ & $15 \%$ \\
\hline $\mathrm{D}$ & $25 \%$ & $15 \%$ & $15 \%$ & $45 \%$ \\
\hline $\mathrm{E}$ & $25 \%$ & $35 \%$ & $25 \%$ & $15 \%$ \\
\hline
\end{tabular}

\section{Alat Penelitian}

Alat yang digunakan pada penelitian ini disajikan pada tabel berikut:

Tabel 2. Alat penelitian

\begin{tabular}{|l|l|l|}
\hline No & Nama Alat & Kegunaan \\
\hline 1 & $\begin{array}{l}\text { Cetakan } \\
\text { Paving } \\
\text { block }\end{array}$ & $\begin{array}{l}\text { Untuk mencetak } \\
\text { paving blok }\end{array}$ \\
\hline 2 & Timbangan & $\begin{array}{l}\text { Untuk menimbang } \\
\text { bahan penelitian }\end{array}$ \\
\hline 3 & Wadah & Untuk tempat \\
\hline
\end{tabular}

\begin{tabular}{|l|l|l|}
\hline & & pencampuran bahan \\
\hline 4 & $\begin{array}{l}\text { Sendok } \\
\text { semen }\end{array}$ & $\begin{array}{l}\text { Untuk } \\
\text { mencampurkan } \\
\text { bahan }\end{array}$ \\
\hline 5 & $\begin{array}{l}\text { Alat Uji } \\
\text { tekan }\end{array}$ & $\begin{array}{l}\text { Menguji kekuatan } \\
\text { paving }\end{array}$ \\
\hline 6 & $\begin{array}{l}\text { Kertas } \\
\text { Label }\end{array}$ & $\begin{array}{l}\text { Untuk melabel } \\
\text { sampel }\end{array}$ \\
\hline 7 & Kost tangan & $\begin{array}{l}\text { Untuk melindungi } \\
\text { tangan }\end{array}$ \\
\hline
\end{tabular}

Sumber : data primer, 2017

\section{Variabel Penelitian}

\section{a. Variabel bebas}

Variabel bebas dari penelitian ini adalah berupa variasi komposisi bahan.

Tabel 3. Variasi komposisi bahan

\begin{tabular}{|l|l|ll|}
\hline No & Nama bahan & Fungsi bahan \\
\hline 1 & Slag nikel & $\begin{array}{l}\text { (pengganti } \\
\text { kasar) }\end{array}$ & agregat \\
\hline 2 & $\begin{array}{l}\text { Abu sekam } \\
\text { padi }\end{array}$ & $\begin{array}{l}\text { (pengganti } \\
\text { kasar) }\end{array}$ & agregat \\
\hline 3 & Ply ash & $\begin{array}{l}\text { (pengganti } \\
\text { kasar) }\end{array}$ & agregat \\
\hline 4 & Semen & $\begin{array}{l}\text { Sebagai } \\
\text { material }\end{array}$ & perekat \\
\hline 5 & Air & $\begin{array}{l}\text { Sebagai } \\
\text { pelarut }\end{array}$ & bahan \\
\hline
\end{tabular}

Sumber : data primer, 2017

b.

\section{ariabel terikat}

Variabel terikat dari penelitian ini adalah berupa kuat tekan dan berat paving block

\section{Prosedur Penelitian}

Adapun prosedur kerja yang akan dilakukan pada penelitian ini adalah sebagai berikut:

\section{a. Tahap preparasi Sampel \\ 1) Preparasi Slag nikel}


Slag nikel yang digunakan dalam penelitian ini diperoleh PT Antam pomalaa dalam bentuk biji - bijian, dimana biji slag yang digunakan dalam penelitian ini berjenis F3 dan F4 yang kemudian sampel tersebut selanjutnya ditimbang menggunakan timbangan berdasarkan komposisi variasi bahan pada Tabel 3. kemudian siap untuk dicampurkan dengan bahan lain.

2)

\section{reparasi Abu Sekam Padi}

Adapun pembakaran sekam padi yaitu, hasil sisa penggilingan gabah padi menjadi beras, kemudian sekam padi dibakar hingga menjadi abu, setelah itu abu dapat digunakan sebagai sampel.

\section{3) Preparasi Fly ash}

Fluidized bed system adalah sistem dimana udara ditiup dari bawah menggunakan blower sehingga benda padat di atasnya berkelakuan mirip fluida.Teknik fluidisasi dalam pembakaran batubara adalah teknik yang paling efisien dalam menghasilkan energi. Pasir atau corundum yang berlaku sebagai medium pemanas dipanaskan terlebih dahulu. Pemanasan biasanya dilakukan dengan minyak bakar.Setelah temperatur pasir mencapai temperature bakar batubara $\quad\left(300^{\circ} \mathrm{C}\right) \quad$ maka diumpankanlah batubara. Sistem ini menghasilkan abu terbang dan abu yang turun di bawah alat. Abu-abu tersebut disebut dengan fly ash dan bottom ash.

\section{4) Tahap pembuatan paving block}

Adapun pembuatan benda uji dilakukan sebagai berikut :

a) Menyediakan bahan-bahan campuran paving block yaitu Slag nikel, abu sekam padi, ply ash, semer, dan air seperti pada Tabel 4. Komposisi perbandingan variasi paving block dibawah ini :

Tabel 4. Variasi komposisi bahan

\begin{tabular}{|l|l|l|l|l|}
\hline $\begin{array}{l}\text { Samp } \\
\text { el }\end{array}$ & $\begin{array}{l}\text { Seme } \\
\mathrm{n}\end{array}$ & $\begin{array}{l}\text { Slag } \\
\text { nikel }\end{array}$ & $\begin{array}{l}\text { Abu } \\
\text { sekam } \\
\text { padi }\end{array}$ & $\begin{array}{l}\text { Ply } \\
\text { ash }\end{array}$ \\
\hline A & $25 \%$ & $25 \%$ & $25 \%$ & $25 \%$ \\
\hline B & $25 \%$ & $45 \%$ & $15 \%$ & $15 \%$ \\
\hline C & $25 \%$ & $15 \%$ & $45 \%$ & $15 \%$ \\
\hline D & $25 \%$ & $15 \%$ & $15 \%$ & $45 \%$ \\
\hline E & $25 \%$ & $35 \%$ & $25 \%$ & $15 \%$ \\
\hline
\end{tabular}

Sumber : data primer, 2017

b) Setelah semua bahan disediakan maka dimasukkan bahan pada tempat pengadonan yaitu Slag nikel, abu sekam padi, ply ash, dan semen diaduk sampai rata dan diberi air pada bagian tengah adonan serta dibiarkan $2-5$ menit agar campuran saling mengikat. 
c) Setelah campuran benarbenar homogen atau telah berwarna coklat tanah, adonan dicetak lalu dipress secara menggunakan vibrasi pres untuk dipadatkan, cetakan paving block terbuat dari besi dan berbentuk balok.

d) Paving block yang sudah dicetak diberi nomor indetitas untuk penandaan setiap variasi benda uji. Kemudian dilakukan perawatan dengan cara mengeringkan paving block 1 hari kemudian direndam.

e) Cetakan Paving block yang di gunakan berukuran $20 \mathrm{~cm} \times 10 \mathrm{~cm}$ $\mathrm{x} 6 \mathrm{~cm}$ dengan luas permukan dapat diperoleh dengan rumus :

$$
\mathrm{Lp}=\mathrm{p} \times 1 \times \mathrm{t}
$$

Dimana : $\mathrm{Lp}=$ luas permukaan (cm2)

$$
\begin{aligned}
& \mathrm{p}=\text { panjang }(\mathrm{cm}) \\
& \mathrm{t}=\operatorname{tinggi}(\mathrm{cm}) \\
& \mathrm{l}=\operatorname{lebar}(\mathrm{cm})
\end{aligned}
$$

\section{5) Prosedur pengujian Kuat Tekan Strength) \\ (Compresive}

Pengujian kuat tekan dilakukan untuk mengetahui kuat tekan hancur dari benda uji. Benda uji yang dipakai adalah paving block berbentuk balok dengan ukuran $20 \mathrm{~cm}$ x $10 \mathrm{~cm} \times$ $6 \mathrm{~cm}$. Pengujian kuat tekan dilakukan saat paving block berumur 20 hari. Jumlah paving block yang diuji pada umur 20 hari yaitu 5 buah, yang memiliki komposisi bahan yang berbeda. Adapun prosedur pengujiannya adalah sebagai berikut:

a) Mengeluarkan benda uji setelah berumur 17 hari dari bak perendaman dan diletakkan pada ruangan sampai sampel kering.

b) Sebelum benda uji diberi pembebanan (diberi tekanan dengan alat compression testing machine), diukur kembali masing-masing sisi.

c) Beban tekan yang diberikan secara perlahanlahan pada benda uji dengan cara mengoperasikan tuas pompa sehingga benda uji runtuh.

d) Pada saat jarum penunjuk skala beban tidak naik lagi atau bertambah, maka skala yang ditunjukkan oleh jarum tersebut dicatat sebagai beban maksimum yang dapat dipikul oleh benda uji tersebut.

e) Prosedur ini dilakukan untuk sampel benda uji kuat tekan yang lain.

\section{HASIL DAN PEMBAHASAN}

\section{Hasil Pembuatan Paving block}

Paving block yang terlihat pada Gambar 7 adalah hasil dari proses 
praparasi bahan sampai percetakan bahan. Adapun cetakan yang digunakan pada penelitian ini berbentuk balok dengan ukuran 20 $\mathrm{cm} \times 10 \mathrm{~cm}$ x $6 \mathrm{~cm}$.

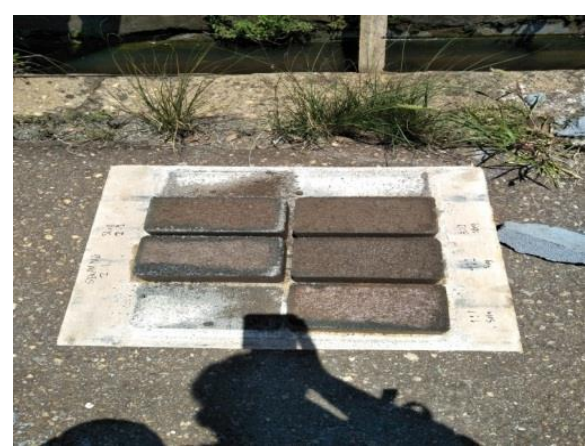

Gambar 5. Hasil percetakan paving block

Paving block yang telah di keringkan selama 24 jam kemudian diberikan perlakuan (perendaman) selama 17 hari dan selanjutnya dikeringkan kembali dan siap untuk dilakukan uji kuat tekan paving dengan menggunakan alat uji tekan beton merek ENERPAC.

\section{Hasil Analisis Uji Tekan Paving block}

Hasil uji tekan paving block untuk sampel A,B,C,D dan E dapat dilihat pada table berikut :

Tabel 5. Kode sampel dan komposisi perbandingan

\begin{tabular}{|l|l|c|l|}
\hline No & \multicolumn{1}{|c|}{$\begin{array}{c}\text { kode } \\
\text { sampel }\end{array}$} & $\begin{array}{c}\text { berat } \\
\text { (gram) }\end{array}$ & \multicolumn{1}{|c|}{ kuat tekan $(\mathrm{kg})$} \\
\hline 1 & A & 2471.7 & 22238 \\
\hline 2 & B & 2476.9 & 15731 \\
\hline 3 & C & 1964.8 & 15731 \\
\hline
\end{tabular}

\begin{tabular}{|l|l|l|l|}
\hline No & $\begin{array}{c}\text { kode } \\
\text { sampel }\end{array}$ & $\begin{array}{c}\text { berat } \\
\text { (gram) }\end{array}$ & \multicolumn{1}{c|}{ kuat tekan $(\mathrm{kg})$} \\
\hline 4 & D & 2236.2 & 8136 \\
\hline 5 & E & 2261.9 & 12698 \\
\hline
\end{tabular}

Sumber : data primer, 2017

Dari tabel diatas terlihat persentase paving block dengan kode sampel C campuran 45\%abu sekam padi, $25 \%$ semen, $15 \%$ slag nikel dan $15 \%$ ply ash dengan waktu perendaman selama 17 hari menghasilkan kuat tekan paving block sebesar $15731 \mathrm{~kg} / \mathrm{cm} 2$, begitu pula pada persentase paving block dengan kode sampel B campuran $25 \%$ semen, $45 \%$ slag, dan $15 \%$ fly ashdengan waktu perendaman yang sama selama 17 hari mengahasilkan kuat tekan paving block sebesar $15731 \mathrm{~kg} / \mathrm{cm} 2$, tapi dua sampel ini menunjukan berat yang berbeda.

Kemudian paving block dengan penambahan beberapa persentase abu sekam padi, slag nikel, dan ply ash menunjukkan hasil kuat tekan yang berbeda-beda. kuat tekan terbaik ditunjukan pada kode sampel A dengan penambahan 25\% abu sekam padi, $25 \%$ slag nikel, dan $25 \%$ ply ash menunjukkan perilaku kuat tekan yang cukup baik di mana nilainya kuat tekannya 22238 $\mathrm{kg} / \mathrm{cm} 2$. Hal ini disebabkan oleh abu sekam padi dan ply ash yang ditambahkan mampu bereaksi dengan material lainnya dan mampu menutupi pori paving block.Namun, perlu diperhatikan bahwa abu sekam 
padi mempunyai daya serap yang tinggi terhadap air.

Perilaku hampir sama ditunjukkan oleh kode sampel B dan C dengan $45 \%$ slag dan $45 \%$ abu sekam padi. Nilai kuat tekan masingmasing sampel selalu berada di bawah nilai kuat tekan beton.Hal ini disebabkan jumlah abu sekam padi yang lebih besar menyebabkan air yang dicampurkan tidak sepenuhnya digunakan untuk bereaksi mengikat material pembentuk beton namun diserap oleh abu sekam padi yang tercampur dalam beton. Sehingga nilai kuat tekan paving block pada usia 20 hari menjadi menurun. Hal ini dimungkinkan oleh abu sekam padi yang menyerap air lebih banyak menyebabkan pori dalam paving block lebih banyak yang kosong sehingga ketika beban bekerja paving block tidak mampu bekerja dengan baik.

Selain itu ketika semen, slag nikel, abu sekam padi, dan ply ash dicampur dengan air, timbulah reaksi kimia antara campuran campurannya dengan air. Reaksireaksi ini menghasilkan bermacammacam senyawa kimia yang menyebabkan ikatan dan pengerasan. Adapun unsur yang paling berpengaruh dalam menentukan kekuatan paving block ialah silikat (SiO2), unsur ini bekerja sebagai pengikatan semua campuran paving sehingga berbentuk keras dan bersatu antara satu dengan yang lainnya (Bakhtiar A, 2012).

E. ESIMPULAN DAN SARAN

1. K esimpulan

Berdasarkan hasil penelitian dan pembahasan yang telah dilakukan diperoleh kesimpulan bahwa : Variasi komposisi bahan terhadap kuat tekan paving block mengalami hasil kuat tekan yang berbeda-beda. Dimana hasil optimum kuat tekan terdapat pada pencampuran paving block A : semen $25 \%$, slag $25 \%$, sekam padi $25 \%$, ply ash $25 \%$ yaitu sebesar $103.86 \mathrm{~kg} / \mathrm{cm} 2$ dan adapun sampel penelitian yang menunjukan nilai uji kuat tekan yang cukup rendah ditunjukan pada sampel D : semen $25 \%$, slag $15 \%$, sekam padi $15 \%$, ply ash $45 \%$.

Kode sampel A menunjukan kuat tekan yang optimum dibandingkan dengan semua sampel. Hal ini disebabkan karena jumlah tiap material komposisi bahan merata yaitu 25\% semen, 25\% slag nikel, $25 \%$ abu sekam padi, dan $25 \%$ fly ash. Dengan komposisi material yang merata dimana silika (Si) dan alumina (Al) membantu membantu menekan kandungan senyawa kimia sodium (Na) dan potassium $(\mathrm{P})$ yang terkandung dalam fly ash.Variasi komposisi bahan pada kode sampel $\mathrm{B}$ dan $\mathrm{C}$ menunjukan kuat tekan yang sama namun terdapat perbedaan berat diantara kedua sampel tersebut dimana sampel $\mathrm{C}$ 
lebih ringan dibandingkan dengan sampel B. Hal ini disebabkan karena pada sampel $\mathrm{C}$ penambahan abu sekam padi lebih banyak yaitu sebesar $45 \%$ hal itu menyebabkan air dalam campuran beton terserap dan juga material abu sekam padi tergolong sangat ringan.

\section{Saran}

Berdasarkan dari hasil penelitian dan kesimpulan diatas dapat diberikan saran-saran sebagai berikut :

a. Pada saat proses pencampuran hendaknya dapat disebarkan secara merata sehingga secara langsung adukan campuran menjadi homogen.

b. Perlu adanya penelitian lanjutan dengan variasi penambahan yang berbeda, untuk mendapatkan nilai yang optimal.

c. Perlunya perawatan paving block dengan cara perendaman dalam waktu tertentu.

d. Perlu adamnya penelitian lanjutan yang lebih kreatif dalam memamfaatkan slag nikel, abu sekam padi, dan ply ash

F.

AFTAR PUSTAKA

Anonim, 1987. Ubin Semen (SNI 03-0028 1987). Bandung :Departemen Pekerjaan Umum, Yayasan Lembaga Penyelidikan Masalah Bangunan
Anonim, 1989. Bata Beton untuk lantai (SNI 03-0691-1989) Bandung Departemen Pekerjaan Umum, Yayasan lembaga Penelidikan masalah bagunan.

Anonim, 2002, Standar Nasional Indonesia, SK SNI-151990-F, Bandung: Departemen Pekerjaan Umum

Alflan, 1998. Tingkat Kandungan Air Serta Pengaruhnya Terhadap Kerusalum Pada Permulraan Plasteran Dinding. Pekanbaru: Lembaga Penelitian UNRL

Ashad. H, 2005. Kontribusi Nickel Slag-Cement terhadap Kekuatan dan Durabilitas Beton Kinerja Tinggi. Tesis Program Magister, Institut Teknologi Bandung.

Bakhtiar A, 2012. Studi Peningkatan Mutu Pavingblock dengan Penambahan Abu sekam Padi

Lukito, P. 1999. Abu Sekam Padi sebagai material untuk meningkatkan kuat tekan Beton, Tesis S2, Program Studi Teknik Sipil, Prof,rram Pasca Sarjana, Universitas Gadjah Mada, Yogyakarta.

Wayan. M.,dkk. 2016. Penggunaan Terak Nikel sebagai Agregat dalamCampuran

Beton.Mahasiswa Program Magister Teknik Sipil, Program Pascasarjana. Universitas Udayana. Denpasar 
Wintoko, B., 2012, Sukses Wirausaha Batako Dan Paving block, Pustaka Baru Press.Pekan Baru.

Murdock, L.J, and Brook K. M., 1991, Bahan dan praktek Beton (alih bahasa Stephanus Hendarko), Erlangga: Jakarta

Purnama, E, 1995, Pengaruh Abu Sekam Padi (Rice Hush Ask) ada Kuat tekan Beton, l'GA S-1 Teknik Sipil FakultasTeknik Universitas Gadjah Mada, Yogyakarta

Saptahari.S, Lelyani. K .K. 2010. Penggunaan Terak Nikel Sebagai Agregat pada Beton Mutu
Saptahari.S, Louis, 2003, Penggunaan Terak Nikel Sebagai Agregat Beton Pemberat Pipa Gas Lepas Pantai, Tesis Program Magister, Institut Teknologi Bandung

Sugiri Saptahari, Lelyani Kin Khosama, 1997, Penggunaan Terak Nikel Sebagai gregat pada Beton Mutu Tinggi. Tesis Program Magister, Institut Teknologi Bandung. Tinggi.Tesis Program Magister, Institut Teknologi Bandung. 